\title{
The Physical and Optical Societies' Exhibition of Apparatus.
}

THE fifteenth annual exhibition of apparatus held by the Physical and Optical Societies at the Imperial College of Science and Technology, South Kensington, brought to light a larger number than usual of novel and improved instruments. The standard of workmanship and finish was everywhere high, and it was a pleasure to note that the products of British firms, to which the exhibition was primarily devoted, compare very favourably in these respects as well as in ingenuity and soundness of design with imported goods of a similar character. There was a preponderance of instruments for industrial purposes and for advanced research: a certain number of firms also showed apparatus suitable for educational laboratories, but a greater proportion of apparatus of this type would be welcome at such an exhibition. Special interest also attaches to disassembled instruments : a brass box with knobs is impressive rather than instructive.

In briefly discussing some of the exhibits it is impossible to do justice to most of the stands, which could not be adequately studied in an exhibition lasting only two days. It will be necessary to make an arbitrary selection of apparatus which appeared to be specially interesting on account of its novelty, and to pass over without mention a majority of items the intrinsic importance of which is at least as great.

The most sensational feature of the exhibition was Mr. C. F. Elwell's discourse on "Talking Motion Pictures," illustrated by demonstration films. It must suffice here to remark that no one who saw and heard the demonstration can doubt that the essential problem has been solved, and that for better or worse the talking picture is ripe for commercial exploitation. In addition to other items making for brighter physics, visitors had the piquant experience of being addressed by a very realistic President Coolidge on the American citizen's burden of taxation! An equally interesting discourse and demonstration was given each day by Mr. F. Twyman, who dealt with the Michelson interferometer. In the hands of Mr. Twyman and his assistant, this interferometer became a delicate means for studying temperature distribution in a transparent body: the instrument was so adjusted as to project on the screen a field of substantially uniform colour derived from a source of white light, and on the introduction of the demonstrator's finger into one of the interfering light-beams, lines of colour appeared round the shadow of the finger, these lines representing approximately isothermal contours. Perhaps the most striking of the experiments shown was the "soaking in " of the isothermal lines into a plate of glass when a match had been momentarily applied to the latter, and it was also made possible to "see " petrol vapour poured from a bottle and the lines of strain in glass under stress-the latter application giving effects similar to those which have been obtained by Prof. E. G. Coker with polarised light.

The Cambridge Instrument Company is one of the firms which enters into the spirit of the exhibition and seeks to enhance its interest by the variety of its exhibits and by admirable descriptions given in the programme. The principal metier of the firm, the measurement of temperature, was represented by some dial thermometers of the vapour-pressure type, but they were somewhat overshadowed by more intriguing " side-lines." The dial thermometer appears to be displacing the glass thermometer from industry, for Negretti and Zambra also made a feature of thermometers in which a mercury bulb communicates with a dial-control through steel-lined tubing. An interesting improvement in calorimetry is the use of stainless steel in a bomb calorimeter (Griffin). For taking the temperature of buried cables, Siemens measures the resistance of a nickel pilot wire fitted to the latter.

Items of interest to meteorologists included an Assmann psychrometer ventilated by an electrically driven centrifugal fan, shown by Negretti and Zambra. It is to be hoped that this or a similar firm will succeed in solving the hitherto unsolved problem of constructing a self-acting hygrometer with permanent zero: apart from this latter consideration the firm's recording hair hygrometers appear to be fool-proof A simple and ingenious recording barometer of great sensibility (Hughes) is that designed by S. G. Starling: the mercury bulb is connected to the vertical column of the barometer by a horizontal tube of substantial length, the whole being mounted on a pivoted board hanging in a vertical plane. Movement of the mercury causes the board to tilt, while a pen carried by the board traces a record on a chronometric drum. Short and Mason, by a special design of the linkwork controlling the pen of a barograph, are able to provide the latter with an exceptionally open scale. A novel kind of cloud photograph is taken with the Robin Hill lens (Beck), which has an angle of $\mathrm{I} 80^{\circ}$, so that a photograph of the whole sky can be taken on a single plate. Such a photograph is of value in spite of its distortion, but if necessary a selected section of it can be straightened out by copying with the lens reversed.

Two interesting oscillographs were those shown respectively by Tinsley and Co. and by the Cambridge Instrument Co. The former is of the inertia-less cathode-ray type and employs a hot cathode, high sensibility with low voltage being thus secured. The cathode stream is focussed into a pencil by surrounding the filament with a positivelv charged sheath. The Cambridge instrument, on the other hand, is an improvement on the Duddell oscillograph and enables simultaneous records to be obtained from three separate vibrators which are replaceable and may be electrostatic or electromagnetic in any combination. Intense illumination is secured by applying a momentary excess voltage to the 4-volt metal filament lamp during and immediately before exposure of the travelling photographic film. The Campbell frequency meter, which aroused much interest when it was recently described before the Physical Society, was also shown by this firm. It depends on a bridge system employing mutual inductances, covers a range of from 200 to 4000 cycles, and attains an accuracy of about $\mathrm{I} / \mathrm{Io}$ per cent. Other meters worth noting were a series for various quantities (ammeters, voltmeters, etc.) but uniform exterior by the Weston Electrical Instrument Co. These are of convenient square form but comparable in price with those of less portable design. A very interesting detail of design has been introduced into the Cirscale movingiron instruments (Record Electrical Co.) in order to secure a pointer movement of $300^{\circ}$. These instruments are of the type in which a pair of soft iron strips inside a solenoid are magnetised by the same field, so that the repulsion between them measures the energising current. In the present instance, two pairs of such strips are used: one member of the first pair is fixed, while the " fixed" member of the second pair is carried round by the moving member of the first pair, the two latter members being rigidly joined together but spaced apart along the axis of the solenoid. The Rayworth's voltmeter (Elliott Bros.) for testing accumulators is provided with a 
differential winding and a cadmium electrode so arranged that, in addition to ordinary testing, comparison of the potential of each plate with that of the cadmium electrode can be carried out, and further, the unexpended charge remaining in the cell can be measured. The Darimont electric batteries have the interesting feature that the exciting and depolarising solutions are separated by a semi-permeable membrane created by the reaction which takes place between the solutions themselves.

For testing overhead A.C. mains, Crompton and Co. provide a hinged-core transformer. The ring-shaped core is passed over the main and closed so as to surround the latter, which then forms the primary of the transformer, while the winding on the core forms a secondary and enables the current in the main to be tested. Impedance apparatus included the Duwatcon condenser for wireless (Dubilier Condenser Co.), so designed that its range for series connexion slightly overlaps its range for parallel connexion, thus obviating the gap in tuning range which ordinarily occurs when the connexion is changed; and three interesting variometers. Of these the Mansbridge is flat in shape and comprises D-shaped coils: used alone it will cover all the B.B.C. wave-lengths, and in conjunction with a fixed condenser of $0.002 \mu f$ will cover wave-lengths up to 1800 metres. A similar range is attained in a variometer by the Marconiphone Co. by means of a series-parallel switch. In the "wound on air" variometers of the Igranic Electric Co. the windings are spherical and entirely self-supported.

Amongst wireless apparatus, the Multivibrator wavemeter designed by D. W. Dye (Sullivan) attracted much attention. In this arrangement a specially constant tuning-fork, maintained in vibration by a thermionic valve, controls by accordance a multivibrator comprising two valves so cross-coupled as to generate oscillations rich in harmonics at approximately the same fundamental frequency as the fork. By selective amplification, harmonics up to the I 20 th can be picked out and heterodyned with the oscillation the frequency of which is to be measured, and by using two such arrangements in series a harmonic of frequency $\mathrm{I} \cdot 2 \times \mathrm{IO}^{6}$ can be utilised. A complete "public address system" for amplifying speech or gramophone reproductions was shown in action by Marconi's W. T. Co., high-power water-cooled valves as used for broadcast transmission by the M.O. Valve Co., and the newest types of dull-emitter and other valves by the latter, the Mullard Radio Valve Co., and Cossor. A fool-proof emergency wireless transmitter for ships' lifeboats was shown by Evershed and Vignoles.

As regards line telegraphy, it was gratifying to notice a column printer of British manufacture (Creed and Co.): Morse line currents are converted to printed matter arranged in columns like that given by an ordinary typewriter, as in the American instruments which have hitherto held the field. The direct-working sounder of the India Rubber, etc. Works Co. introduces the long overdue reform of replacing the pony sounder by a far more efficient device employing a diaphragm.

A radium clock has been devised by $\mathrm{Mr}$. Harrison Glew the radium for which may be that contained in an ordinary applicator or other container which can be removed from the clock when desired : in fact, the period of the clock may be used as a measure of the quantity of radium in any vessel to which it is connected. An interesting high-voltage high-resistance battery useful in radio-active and ionisation work is the disc battery designed by Major C. E. S. Phillips (Cambridge Instrument Co.). It consists of adjacent paper discs coated with metal foil, is very portable, and is not damaged by short-circuiting. The horrors of the dentist's chair may be shortened by the use of radiography: in the apparatus provided by Watson and Sons all external high tension leads are eliminated for the benefit of dentists untrained in such matters, and for the peace of mind of their patients. A Potter Bucky diaphragm is also provided for cutting out secondary radiation from the patient's body, which otherwise impairs the definition of the radiograph : it consists of a grid of lead plates so arranged as to absorb radiation which deviates from the direct line, and it is kept in motion during exposure so that its shadow does not appear on the film.

A soft-ray tube for crystal work, designed by Shearer, was shown by Hilger connected with a highly efficient evacuating arrangement. This comprised a Hyvac backing pump (on the Gaede model but with optically perfect contact surfaces) in combination with a Vitreosil mercury condensation pump (Edwards and Co.) with a fused silica casing, the over-all speed being about 200 c.c. per second and the ultimate vacuum about $0.000002 \mathrm{~mm}$. An even faster pump is the Kaye-Backhurst, which is all of metal and employs an annular jet of vapour from boiling mercury to entrap molecules diffusing from the evacuated space. The speed amounts to some thousands of cubic centimetres per second.

Messrs. Hilger also showed how to use a LummerGehrcke plate in combination with a spectroscope to demonstrate the Zeeman effect, obtaining very clear definition. Other optical items were a Nicol prism of $\mathrm{I} \frac{1}{\mathrm{~g}}$-in. aperture (Bellingham and Stanley); a scaleometer (Ottway and Co.) comprising a pocket microscope with a scale in the focal plane of the eyepiece and an oblique glass plate for illuminating the object and a rod illuminator (Baker) for microscopes. The latter very curious and effective device consists of a thick glass rod bent to any convenient shape and capable of carrying light by total internal reflection from a light source to a microscope : in fact it forms a kind of hose for conveying light. A selenium photometer (Watson and Sons), recently described by Dr. Toy, has been specially designed for measuring the density of photographic negatives. Two beams of light from the same source reach a selenium cell by different paths, and a screen can be turned so as to cut out one beam and let in the other at the same rate. The negative is interposed in the path of one beam and an adjustable wedge in that of the other, so that when the opacities of these obstructions are equal, no change in the illumination of the selenium cell is produced by turning the screen.

Teachers will be interested to find that kinematograph projectors for private use are coming within the reach of small pockets. A Pathé projector (Baker) can now be obtained at a comparatively moderate price, while a more expensive outfit (Kodak) enables the user to take his own films as well as to project them, the films being reversed to positive without the use of a negative. A Leitz photomicro. graph (Ogilvy and Co.) has been so arranged that all the operations necessary in photographing microscopic objects on a whole plate can be performed from a single position of the observer, and the apparatus is suspended on springs while the exposure is actually being made. While discussing optical apparatus it is worth while to note that pointolite lamps can now be obtained for use on A.C. mains.

A very simple planimeter shown by Harling consists of a single rigid piece of metal carrying a tracing point at one end and a hatchet-shaped projection, the plane of which passes through the point, at the

NO. 288 I, VOL. I I 5$]$ 
other. The point is passed round a closed curve in the ordinary way, and the distance between the positions of the hatchet edge before and after this operation is a measure of the area encompassed. It is claimed that this simple device can give an accuracy of 2 per cent.

Surveying instruments included a tacheometer (Cooke, Troughton and Simms) in which the horizontal distance of a surveyor's vertical scale is given directly, allowance for the slope being made by an automatic cam-operated adjustment of the distance between the stadie lines in the focal plane of the eyepiece with which the image of the scale is compared. Dr. Hutchinson's goniometer (Swift and Son) was also worth noting on account of its versatility: it serves as an ordinary goniometer, an axial angle apparatus, a Kolrausch total reflectometer, and a prism refractometer. An ingenious balance (Oertling and Co.) called the "Chainomatic" dispenses with all weights and riders below O.I gm. by employing a chain attached at one end to an arm of the balance and at the other to a pillar which can be raised and lowered to a measured extent without opening the case. The position of the pillar indicates how much of the weight of the chain is being borne by the balance arm. In the tank gauge made by Negretti and Zambra for indicating liquid levels, air is pumped into a tube extending down into the liquid until it escapes from the bottom: the tube is then put into communication with a pressure gauge which registers the head of liquid in the tank. Another instrument of mechanical interest is the recording accelerometer of the Cambrids? Instrument Co., in which an eccentric mass, the movements of which are made deadbeat by Foucault-current damping, records accelerations by the "stylus-on-celluloid", method developed by this firm.

A fuller account of many of the exhibits will be found in the December issue of the Journal of Scientific Instruments published by the Institute of Physics. The issue is entirely devoted to the South Kensington exhibition.

The following firms participated in the exhibition : C. Baker (optical instruments), R. and J. Beck, Ltd. (optical instruments), Bellingham and Stanley, Ltd. (optical instruments), W. Butcher and Sons, Ltd. (the optiscope projection apparatus and the autoprint photographic enlarger), the Cambridge Instrument Co., Ltd. (thermometric and various precision instruments), the Cambridge University Press, Carbic, Ltd. (the Otis King's calculator), the Chromoscope Co., Ltd. (the mutochrome, for varying the colours in patterns and designs), Cooke, Troughton and Simms, Ltd. (surveying instruments), A. C. Cossor, Ltd. (thermionic valves), Creed and Co., Ltd. (print- ing telegraphs), Crompton and Co., Ltd. (electric laboratory apparatus), George Culver, Ltd. (opticians' goods), J. H. Dallmeyer, Ltd. (cameras and lenses), the Damard Lacquer Co., Ltd. " Formite" bakelite synthetic resin products for insulation, etc., the hardness of which is suggested by a humorist to have given rise to the company's name), Darimont Electric Batteries, Ltd., F. Davidson and Co. (optical instruments), the Dubilier Condenser Co. (I92r), Ltd. (impedances), Edison Swan Electric Co., Ltd. (pointolite lamps), W. Edwards and Co., Ltd. (vacuum pumps), Elliott Bros. (London), Ltd. (electrical testing apparatus), Everett, Edgecumbe and Co., Ltd. (electric testing apparatus), Evershed and Vignoles, Ltd. (electric tests, wireless, traction recorder for electric trains), Foster Instrument Co. (pyrometers), E. B. Fry, Ltd. (time measuring and lantern slides), A. Gallenkamp and Co., Ltd. (electric furnaces, etc.), Gambrell Bros., Ltd. (electric testing), F. Harrison Glew (radio-active apparatus and cobalt steel magnets), John J. Griffin and Sons, Ltd. (potentiometers, etc.), W. H. Harling (drawing instruments), Adam Hilger, Ltd. (optical and spectrographic instruments), Henry Hughes and Son, Ltd. (compasses, range-finder, etc.), Igranic Electric Co., Ltd. (wireless parts), the India Rubber, Gutta Percha and Telegraph Works Co., Ltd. (telegraph apparatus), Geo. Kent, Ltd. (air, gas and steam meters), Kodak, Ltd. (cameras, etc.), H. K. Lewis and Co., Ltd. (scientific publications), Macmillan and Co., Ltd. (scientific publications), Marconi's Wireless Telegraph Co., Ltd., the M. O. Valve Co., Ltd. (wireless valves), the Mullard Radio Valve Co., Ltd. (Holweck molecular pump and valves), Nalder Bros. and Thompson, Ltd. (electric testing instruments, etc.), Negrettiand Zambra (meteorological instruments), Newton and Co. (optical projectors), L. Oertling, Ltd. (balances and the Eötvös torsion balance), Ogilvy and Co. (microscopes and accessories), W. Ottway and Co., Ltd. (surveying instruments, etc.), Record Electrical Co., Ltd. (switchboard apparatus), Ross, Ltd. (optical and photographic instruments); Short and Mason, Ltd. (meteorological instruments), Siemens Bros. and Co., Ltd. (electric thermometry), H. W. Sullivan, Ltd. (high frequency, cable and other electric testing apparatus), J. Swift and Son, Ltd. (industrial microscopes, etc.), $\mathrm{H}$. Tinsley and Co. (electric testing, etc., apparatus), Watson and Sons (Electro-Medical), Ltd. (X-ray apparatus), W. Watson and Sons, Ltd. (optical instruments), Weston Electrical Instrument Co., Ltd. (electric testing apparatus), Wireless Press, Ltd. The Wireless World and Radio Review, Wray (Optical Works), Ltd. (cameras, lenses, and the nephelometer for measuring opalescence), Zenith Manufacturing Co. (resistances, etc.).

\section{Annual Meeting of the Science Masters' Association.}

THE twenty-fifth annual meeting of the Science Masters' Association was held on January 5, 6, and 7 at the University of Leeds, at the kind invitation of the University authorities. Members were housed at the University Hostels, an act of hospitality which was very much appreciated. The fact that the meeting was held at Leeds gave those members residing in Scotland and the North of England an excellent opportunity of attending, and the number present was very large. The meeting began with a dinner in the Refectory, at which the Association was entertained by the University. Afterwards there was a reception in the Great Hall by the Vice-Chancellor, Dr. J. B. Baillie, and the President of the Association, Sir Berkeley Moynihan, Bart., professor of clinical surgery in the University.
After a delightful speech of welcome by the ViceChancellor, which was suitably acknowledged by the chairman of the Association, Mr. E. A. Gardiner (Louth Grammar School), Sir Berkeley Moynihan delivered his presidential address. The subject he chose was the debt which science owes to medicine, and was introduced by an historical survey of the progress of medicine from the earliest days to the present time. Claiming that Hippocrates and Galen were the inventors of the inductive and deductive methods respectively in science, the president passed in rapid review the events of succeeding centuries and astonished his audience by showing how many eminent men of science had been physicians or surgeons. Although, for several centuries, the growth of medicine scarcely kept pace with that of the slowest

$$
\text { NO. } 288 \text { I, VOL. I I } 5]
$$

